\title{
The measurement of proprioceptive accuracy. A systematic literature review
}

Áron Horváth ${ }^{1,2 *}$, Eszter Ferentzi ${ }^{2}$, Kristóf Schwartz ${ }^{1,2}$, Nina Jacobs ${ }^{3}$, Pieter Meyns ${ }^{3}$, Ferenc Köteles ${ }^{2}$

1 Doctoral School of Psychology, ELTE Eötvös Loránd University, Budapest, Hungary

2 Institute of Health Promotion and Sport Sciences, ELTE Eötvös Loránd University, Budapest, Hungary

3 Rehabilitation Research (REVAL), faculty of Rehabilitation Sciences, University of Hasselt, Hasselt, Belgium

*Correspondence:

Áron Horváth

e-mail: horvath.aron@ppk.elte.hu

address: Bogdánfy Ödön u. 10., H-1117 Hungary

\section{Conflicts of Interest and Source of Funding}

Á. H. was supported by the ÚNKP-20-3 New National Excellence Program of the Ministry for Innovation and Technology from the source of the National Research, Development and Innovation Fund (ÚNKP-20-3-II-ELTE-163).

N. J. was supported by the Special Research Fund (BOF) of Hasselt University (BOF19KP08).

All authors declare that there is no conflict of interest. 


\begin{abstract}
Proprioceptive accuracy refers to the individual's ability to perceive proprioceptive information, i.e., the information referring to the actual state of the locomotor system, that originates from mechanoreceptors located in various parts of the locomotor system and from tactile receptors of the skin. Proprioceptive accuracy appears an important aspect in the evaluation of sensorimotor functioning; however, no widely accepted standard assessment exists. In this systematic review, our goal was to identify and categorize different methods that are used to assess different aspects of proprioceptive accuracy. A literature search was conducted in five different databases (PubMed, SPORTDiscus, PsycINFO, ScienceDirect and SpringerLink). Overall, 1139 articles reporting 1346 methods were included in this review. The methods measure eight different aspects of proprioception, i.e., the perception of joint position, movement, trajectory, velocity and the sense of force, muscle tension, weight and size. They apply various paradigms of psychophysics (i.e. the method of adjustment, constant stimuli and limits). The appropriate measurement method should be chosen based on theoretical considerations or ecological validity.
\end{abstract}

\title{
Introduction
}

Appropriate motor control requires proprioceptive information, that originates from the mechanoreceptors located in our locomotor system (Riemann \& Lephart, 2002). To experience proprioception, our body incorporates input from proprioceptors, i. e., muscle spindles (throughout the muscle belly to process information about the length and rate of stretch) and Golgi tendon organs (pass on information about tension and consequently the force of contraction), and mechanoreceptors (Pacinian, Ruffini, Merkel, and Meissner corpuscle end-organs) located in the skin, ligaments as well as joint capsules (Proske \& Gandevia, 2012). Typically developed humans are able to automatically process, integrate, and consciously perceive their body position, movement and muscle tension based on this type of (proprioceptive) information (Stillman, 2002), and use it for goal-oriented motor behavior (Sarlegna \& Sainburg, 2009).

Proprioceptive accuracy refers to the individual differences in the acuity of the perception of proprioceptive information (Goble, 2010; Han et al., 2016). This ability is associated with important aspects of motor control and performance. For example, proprioceptive accuracy is positively associated with sport achievement in elite athletes (Han et al., 2015). Moreover, better proprioceptive accuracy in the elbow joint was found to be 
related to better throwing performance in basketball (Sevrez \& Bourdin, 2015), darts (Feng et al., 2020), and water-polo (Hams et al., 2019). Concerning the negative aspects, worse proprioceptive accuracy predicts a higher chance of getting injured (Cameron et al., 2003); also, as proprioceptive accuracy deteriorates with aging (Goble, 2010), it may contribute to an increased risk of falls (Wingert et al., 2014). It was also shown that physically active individuals are characterized by better proprioceptive accuracy, and physical activity can compensate the negative impact of ageing on proprioceptive accuracy (Ribeiro \& Oliveira, 2007). Proprioceptive training, i.e., "an intervention that targets the improvement of proprioceptive function" (Aman et al., 2015, p. 2), often including proprioceptive accuracy, is an efficient method to prevent injuries and improve motor performance (Aman et al., 2015).

Based on the aforementioned associations, proprioceptive accuracy appears an important characteristic in the evaluation of sensorimotor functioning, for example, for sport selection (Han et al., 2015) or for assessing the risk of injury and falls (Cameron et al., 2003; Hoang et al., 2016; Lord et al., 1994; Witchalls et al., 2012). Also, measuring the change in proprioceptive accuracy is often used to evaluate the effectiveness of different interventions, e.g., various surgery (Isaac et al., 2007), rehabilitation (Edmonds et al., 2003), and warmingup (Subasi et al., 2008) techniques.

There is a wide variety of methods developed to measure various aspects of proprioceptive accuracy. Hillier and colleagues (2015) identified three clusters of methods: joint position detection, passive motion detection, and passive motion direction discrimination. Starting from a different point of view, Han and colleagues (2016) described three paradigms, based on the classical methods developed for psychophysical experiments (Gescheider, 1997); these paradigms are the (1) joint position reproduction test, that is based on the method of adjustment, i.e., participants have to adjust the level of a stimulus to a reference; (2) active movement extent discrimination apparatus, that is based on the method of constant stimuli, i.e., the stimuli are presented in pairings, and participants have to compare them; and (3) threshold to detection of passive motion, that is based on the method of limits, i.e., participants have to indicate when they perceive the appearance or disappearance of a stimulus (Gescheider, 1997; Han et al., 2016). An important limitation of these reviews is the relatively narrow definition of proprioception. Han and colleagues (2016) defined proprioceptive accuracy as "an individual's ability to integrate the sensory signals from mechanoreceptors to thereby determine body segment positions and movements in space" (Han et al., 2016, p. 81). This account does not take into consideration important aspects of proprioception such as the perception of heaviness, force, and muscle tension (Proske $\&$ 
Gandevia, 2012). Similarly, the review of Hillier and colleagues (2015) also included only a narrow range of methods, namely: joint position detection, passive motion detection threshold and passive motion direction detection.

The primary goal of the present systematic review was to identify and categorize the methods developed and used to measure proprioceptive accuracy in a comprehensive way, i.e., taking into consideration all important aspects of proprioception (i.e. sense of joint position and movement, force and heaviness). With this, the paper could help practitioners and researchers to find the method that suits their needs best for the assessment of proprioceptive accuracy.

\section{Methods}

The study was registered at PROSPERO (CRD42020209136). While conducting this review, we followed the recommendations of the PRISMA (Preferred Reporting Items for Systematic Reviews and Metal-Analysis) statement (Liberati et al., 2009). The search and selection strategy are summarized in Table 1 . The abstracts and titles of the articles were searched in 5 different databases (PubMed, SPORTDiscus, PsycINFO, ScienceDirect and SpringerLink), including every available article (i.e. not only free text articles), without a restriction to publication date. The following search terms were used:

("propriocept*")

AND

("accuracy" OR "acuity" OR "ability" OR "abilities" OR "awareness" OR "sensibility" OR "sensitivity" OR "weight discrimination" OR "movement discrimination" OR "movement detection" OR "joint position sense" OR "force sense" OR "movement sense" OR "movement perception" OR "force perception")

The search was conducted at November 11, 2020. Concerning the inclusion criteria, the PICO (Population, Intervention, Control, Outcome) statement was considered: any research in human samples (e.g. clinical, normal) could be included, but not animal studies (Population). The study did not have to contain any intervention (Intervention), or control group (Control), but the outcome variable had to be an objective assessment of proprioceptive accuracy (Outcome). Proprioceptive accuracy was defined as the acuity of perception of proprioceptive information, i.e., the information referring to the actual state of the locomotor system. It includes the processing of input from proprioceptors located in various parts of the locomotor system and from tactile receptors of the skin. It does not include visual and 
vestibular information. Only empirical, peer-reviewed studies written in English were included; dissertations, theoretical papers, and conference materials were excluded. To decide about the inclusion, in the first step two independent readers (K. S., Á. H.) read the titles and abstracts of the papers. An article was excluded in this step only if both authors deemed it ineligible. In the next step, Á. H. read the full text articles and made the final decision about the inclusion. In case of any ambiguity, F. K. and E. F. decided about the inclusion of the article.

Table 1. Most important characteristics of the literature search

\begin{tabular}{|c|c|}
\hline $\begin{array}{l}\text { Keywords } \\
\text { for } \\
\text { literature } \\
\text { search }\end{array}$ & $\begin{array}{l}\text { ("propriocept*") } \\
\text { AND } \\
\text { ("accuracy" OR "acuity" OR "ability" OR "abilities" OR "awareness" OR } \\
\text { "sensibility" OR "sensitivity" OR "weight discrimination" OR "movement } \\
\text { discrimination" OR "movement detection" OR "joint position sense" OR "force } \\
\text { sense" OR "movement sense" OR "movement perception" OR "force } \\
\text { perception") }\end{array}$ \\
\hline Databases & PubMed, SPORTDiscus, PsycINFO, ScienceDirect and SpringerLink \\
\hline Language & English only \\
\hline $\begin{array}{l}\text { Document } \\
\text { type }\end{array}$ & Peer-reviewed empirical article \\
\hline $\begin{array}{l}\text { Inclusion } \\
\text { criteria }\end{array}$ & $\begin{array}{l}\text { Population: any human } \\
\text { Intervention: not necessary } \\
\text { Comparison: not necessary } \\
\text { Outcome: objective measure of proprioceptive accuracy }\end{array}$ \\
\hline $\begin{array}{l}\text { Exclusion } \\
\text { criteria }\end{array}$ & dissertations, theoretical papers, conference materials, non-English articles \\
\hline
\end{tabular}

\section{Results}

\section{Included studies}

Overall, 6378 articles were identified in the database research. After removing the duplicates, 4293 remained. After reading the titles/abstracts, further 2332 articles were excluded, because 
these did not meet the inclusion criteria. Based on the full texts of the remaining 1961 articles, further 822 studies were excluded. In total, 1139 studies were included in the review.

Following this, 1346 proprioceptive accuracy measurements were identified in a total of 1139 papers (Figure 1); in a number of papers, multiple methods for the assessment of proprioceptive accuracy were used in the same sample. After that, measurement techniques were clustered based on their approach to measurement (Table 2). We used two main criteria to categorize the methods: (1) what aspect of proprioceptive accuracy was assessed, and (2) what psychophysical approach was applied. The full list of the included articles is available in Supplementary materials 1 .

Figure 1. Selection process of the articles, based on Moher and colleagues (2009). 

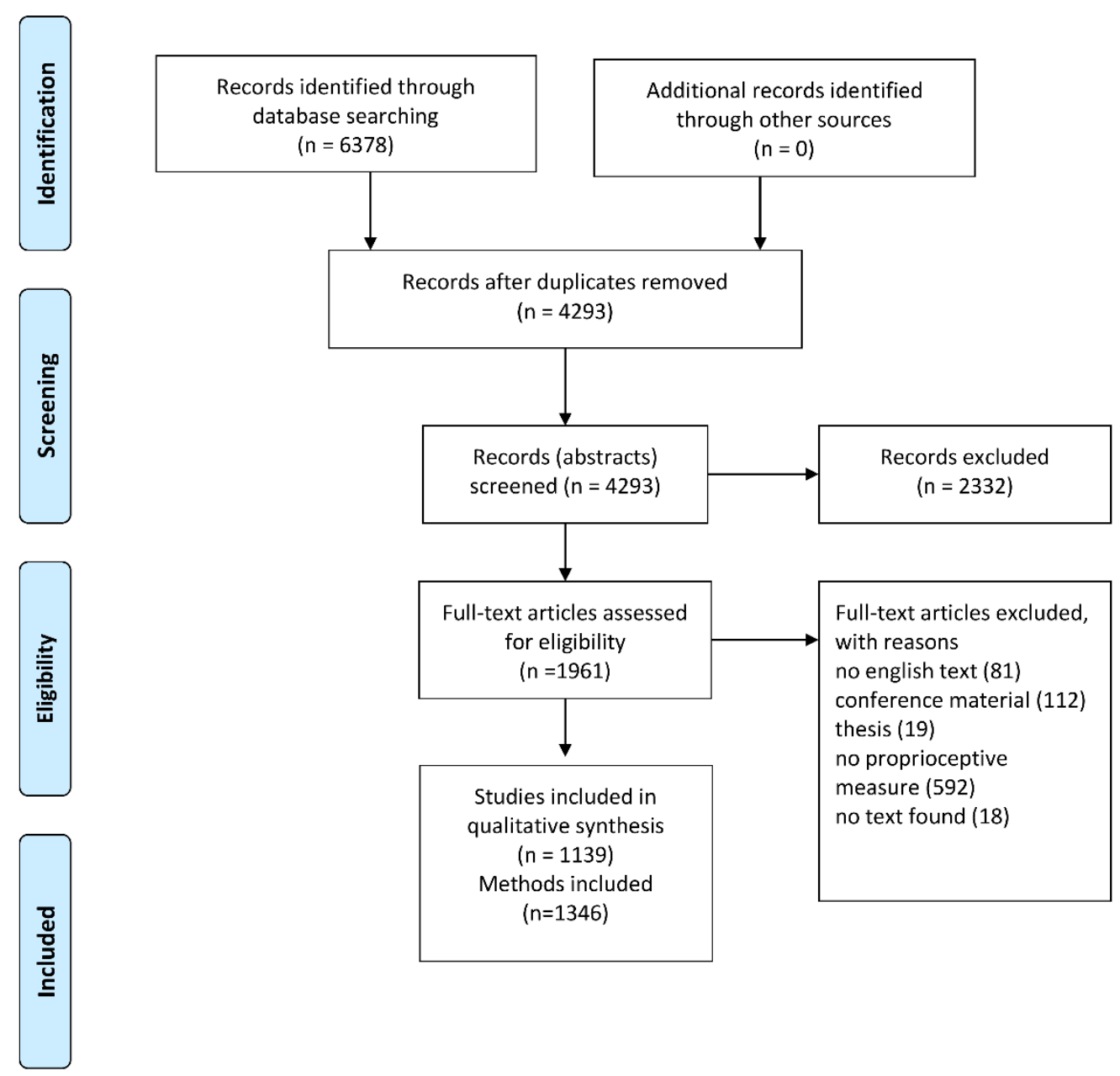
Method of adjustment: Eight different types of proprioceptive accuracy measurements using the method of adjustment were identified.

Joint Position Reproduction ( $\mathrm{n}=836$ ): One of the body parts is set to a target position. One has to reproduce the position of the joint(s) as accurately as possible moving only the joint(s) in question. In different versions of this task, movement can be active or passive and the reproduction may happen with the same or with the contralateral joint (see also the discussion).

Pointing to proprioceptive target $(n=42)$ : One of the body parts is set to a target position. One has to point or reach to the position of the body part as accurately as possible.

Movement Reproduction ( $\mathrm{n}=21)$ : One of the body parts is moved through a given trajectory, with a given velocity, to a given endpoint. Participants are required to reproduce the trajectory, the speed and the endpoint of the movement as accurately as possible.

Trajectory Reproduction ( $\mathrm{n}=2)$ : A body part is moved along a given trajectory. Participants have to reproduce the trajectory of the movement. This can happen with the same or with the contralateral joint.

Velocity Reproduction ( $n=9)$ : A body part is set to move with a given velocity. The task of the participant is to reproduce the speed with the same or with the contralateral body part.

Force Reproduction ( $\mathrm{n}=76)$ : The participant is guided to produce a certain level of force with a muscle or muscle group. After production, they have to reproduce the same force with the same or with the contralateral muscle.

Keep force level $(n=6)$ : Participants have to produce a given amount of (submaximal) force and keep it on the same level.

Muscle Tension Reproduction $(n=1)$ : The participant is asked to produce a given level of muscle tension with a muscle or muscle group. After the production, one has to reproduce the same level of muscle tension as accurately as possible.

Method of constant stimuli: Six different proprioceptive accuracy measurement types were identified that were based on the method of constant stimuli.

Joint Position Discrimination ( $\mathrm{n}=81$ ): Participants have to compare two joint positions and decide whether these were the same or different (note: The Active Movement Extent Discrimination Apparatus (Han et al., 2016) was also categorized as a Joint Position Discrimination tests). 
Movement Discrimination ( $n=6$ ): Participants have to compare two movements (with a given trajectory, velocity and endpoint) and decide if these were the same or not.

Velocity Discrimination $(n=8)$ : Participants have to perform two movement velocities and decide if these were the same or different.

Force Discrimination $(n=5)$ : Participants have to produce a given level of force twice and decide if these were the same or different level of forces.

Weight Discrimination $(n=19)$ : Participants are presented with two objects and have to decide if these are of the same or different weight.

Size Discrimination $(n=3)$ : Participants are presented with two objects and have to decide if these were of the same or different size.

Method of limits: One proprioceptive accuracy measurement technique using the method of limits was identified.

Threshold to Detection of Passive Motion ( $n=231)$ : One body part of the participant is moved passively. The task is to give a signal as soon as the displacement is perceived. This paradigm is based on the ascending method of limits (i.e. the level of stimuli gradually increases until perceived), whereas we did not find any example of the descending method (i.e. level of stimulus gradually decreases until perceiving) to assess proprioceptive accuracy.

Table 2. Summary table of the proprioceptive accuracy measurement techniques.

\begin{tabular}{|c|c|c|c|}
\hline $\begin{array}{l}\text { Aspect of } \\
\text { proprioception }\end{array}$ & $\begin{array}{l}\text { Method of } \\
\text { adjustment }\end{array}$ & $\begin{array}{l}\text { Method of } \\
\text { constant stimuli }\end{array}$ & Method of limits \\
\hline $\begin{array}{l}\text { Joint Position } \\
\text { sense }\end{array}$ & $\begin{array}{l}\text { Joint Position } \\
\text { Reproduction, } \\
\text { Pointing to } \\
\text { proprioceptive } \\
\text { target }\end{array}$ & $\begin{array}{l}\text { Joint Position } \\
\text { Discrimination }\end{array}$ & \multirow{4}{*}{$\begin{array}{l}\text { Threshold to Detection of } \\
\text { Passive Motion }\end{array}$} \\
\hline Movement sense & $\begin{array}{l}\text { Movement } \\
\text { Reproduction }\end{array}$ & $\begin{array}{l}\text { Movement } \\
\text { Discrimination }\end{array}$ & \\
\hline Trajectory sense & $\begin{array}{l}\text { Trajectory } \\
\text { Reproduction }\end{array}$ & N/A & \\
\hline Velocity sense & $\begin{array}{l}\text { Velocity } \\
\text { Reproduction }\end{array}$ & $\begin{array}{l}\text { Velocity } \\
\text { Discrimination }\end{array}$ & \\
\hline
\end{tabular}




\begin{tabular}{|l|l|l|l|}
\hline Force sense & $\begin{array}{l}\text { Force } \\
\text { Reproduction, } \\
\text { Keep force level }\end{array}$ & $\begin{array}{l}\text { Force } \\
\text { Discrimination }\end{array}$ & N/A \\
\hline $\begin{array}{l}\text { Muscle tension } \\
\text { sense }\end{array}$ & $\begin{array}{l}\text { Muscle Tension } \\
\text { Reproduction }\end{array}$ & N/A & N/A \\
\hline Weight sense & N/A & $\begin{array}{l}\text { Weight } \\
\text { Discrimination }\end{array}$ & N/A \\
\hline Size sense & N/A & $\begin{array}{l}\text { Size } \\
\text { Discrimination }\end{array}$ & N/A \\
\hline
\end{tabular}

Note: N/A: no method is available

\section{Discussion}

In this review we attempted to identify and categorize the existing methods used to assess proprioceptive accuracy. Also, we identified eight different aspects or "sense" of proprioception (see Table 2): the ability to perceive (1) joint position, (2) movement, (3) trajectory and (4) velocity, and the level of (5) force and (6) muscle tension, and (7) weight and (8) size of different objects based on proprioceptive information. These aspects can be measured with the classical methods of psychophysics, i.e., the method of adjustment, method of constant stimuli, and the method of limits.

Proprioceptive accuracy can be operationalized by taking different approaches and different paradigms. A common misconception in the literature is that results obtained with the use of one particular methods in one particular body part (joint, muscle) can be generalized. In other words, it is (often implicitly) assumed that a generalizable proprioceptive accuracy exists, and each test measures this general ability. However, empirical studies that investigate the relationship between the results obtained with different methods do not support this assumption. Namely, no association was found between Joint Position Reproduction and Threshold to Detection of Passive Motion (Grob et al., 2002; Janwantanakul et al., 2003), Joint Position Discrimination and Threshold to Detection of Passive Motion (de Jong et al., 2005), Joint Position Discrimination and Joint Position Reproduction (Elangovan et al., 2014), Joint Position Reproduction, Threshold to Detection of Passive Motion and Force Reproduction (Li et al., 2016), Joint Position Reproduction, Velocity Reproduction, Threshold to Detection of Passive Motion, and Force Reproduction (Nagai et al., 2016), Joint Position Reproduction and Force Reproduction (Niespodziński et 
al., 2018), Movement Discrimination and Joint Position Reproduction (Yang et al., 2020), Joint Position Reproduction and Weight Discrimination (Horváth et al., 2021), Force Reproduction and Joint Position Reproduction (Newport et al., 2001). The existence of such a discordance is further supported by studies revealing test-specific differences in certain proprioceptive abilities. For example, Barrack and colleagues (1983) found that dancers perform worse than controls in Joint Position Reproduction test, but are better at Threshold to Detection of Passive Motion with respect to the proprioceptive accuracy of the knee joint. It was also revealed that Force Reproduction test, but not Joint Position Reproduction test is related to ankle instability index (Docherty et al., 2006) and ankle stiffness (Docherty et al., 2004). Another example is that deficits in motor functioning, such as walking disability, sensory disturbance, and central motor conduction time, were only associated with proprioceptive accuracy assessed with the Joint Position Reproduction test, but not with that measured with the Threshold to Detection of Passive Motion test in compressive neuropathy (Okuda et al., 2006). Finally, experimental induced pain influenced the outcome of the Threshold to Detection of Passive Motion test, but did not affect performance in the Joint Position Reproduction test (Sole et al., 2015).

Also, results with respect to one body part cannot be generalized to others. With respect to the Joint Position Discrimination (AMEDA) test, there is a strong correlation between the same joints on the two body sides, but no association between different joints (Han, Anson, et al., 2013; Waddington \& Adams, 1999). In some cases, there is no association between detection threshold when the limb is moved with different speeds (de Jong et al., 2005). Also, results may be joint-position-specific: for example, people with functional ankle instability were shown position-specific deficits in a joint position reproduction task (Yokoyama et al., 2008). Overall, one cannot assess general proprioceptive accuracy from one single test (de Jong et al., 2005), and one always should choose a method that suits the research or practical question at hand best (Nagai et al., 2016).

Moreover, there are other important factors that should be taken into consideration when choosing the appropriate test. Some tests inherently require active effort from the participants (i.e. force reproduction and discrimination, muscle tension reproduction, weight discrimination), but in other cases (e.g. joint position reproduction) the test can be based on passive movement only. For certain patient groups with movement disorders only the passive movement versions are applicable. Because of the tight interaction between the input and output aspects of motor control (Cullen, 2004; Miall \& Wolpert, 1996), active motion involves the processing of both afferent (e.g. the feedback form muscle spindles) and efferent 
(the efference copy of motor command) signals. Therefore, people tend to be more accurate when active muscle activity increases, for example by allowing active motion (Lönn et al., 2001), or increasing shoulder elevation angle (Suprak et al., 2006) and weight bearing (Stillman \& McMeeken, 2001). Weight bearing can also compensate the negative effect of experimentally induced joint effusion (Cho et al., 2011). It also has to be considered, if the reproduction/comparison happens with the ipsilateral or with the contralateral joint. The ipsilateral version requires memory, while contralateral version requires interhemispheric transfer (Goble, 2010). For patients with unilateral/asymmetric movement disorders, the use of the contralateral version is not recommended. Similarly, severe memory impairment might decrease performance in the ipsilateral version of the test. In other words, additional abilities and features beyond the processing of proprioceptive signal(s), can substantially impact performance. Another important factor that can influence the outcome of the assessment is the measured body side, as there might be differences between the dominant and subdominant limb in the processing of proprioceptive information (Goble et al., 2009; Goble \& Brown, 2007, 2008; Han, Anson, et al., 2013; Han, Waddington, et al., 2013).

The approach to proprioception and proprioceptive accuracy used in this systematic review paper is broader than that of previous literature reviews (Han et al., 2016; Hillier et al., 2015). This enabled us to explore methods not included in those reviews. It is worth noting that our definition excluded signals that do not originate in the locomotor system and the skin but might play an important role in the perception of our body, most importantly the visual modality. Also, because of the definition, only methods of assessment that require the subject to consciously being aware of proprioceptive information were included. These factors may limit the ecological validity of proprioceptive accuracy tests. To reach cognitive perception of proprioceptive accuracy, proprioceptive and related somatosensory signals are processed through the conscious relay pathways (i.e. dorsal column/medial lemniscus system) (LundyEkman, 2013). However, in activities of daily life, movement regulation is a dominantly nonconscious (automatic) process, that does not require conscious perception of proprioceptive signals (Gallagher, 2005). Proprioceptive information, that does not reach conscious awareness, is forwarded through the spinal reflex pathway or the spinocerebellar tract to contribute to automatic postural adjustments and balance control (MacKinnon, 2018). As indicated by previous neuro-imaging research, central processing of ankle proprioception can predict balance performance in younger and older adults (Goble et al., 2011). In other words, ankle proprioception will provide important non-conscious feedback regarding the body sway, which is crucial for restoring or maintaining a state of balance. Hence, some researchers 
incorporate 'sense of balance' in the definition of proprioception (Stillman, 2002). Following this, a balance task can be used as an alternative method to (indirectly) assess the ability to use non-conscious proprioception (to keep a state of balance), especially in situations where visual information is eliminated (i.e. participants are blindfolded) (Shumway-Cook \& Horak, 1986). In this way, some researchers attribute increased postural sway (e.g. Romberg test) to loss of proprioceptive sensation (Khasnis \& Gokula, 2003). However, it is important to note that balance control is a complex process depending on multiple sensorimotor mechanisms (Shumway-Cook \& Woollacott, 2007). So, in this way, it can be stated that an increment in postural sway cannot be attributed exclusively to a reduction in proprioceptive information as other sensory feedback systems can play an important role as well (e.g. the vestibular system and other somatosensory senses, such as plantar cutaneous foot sensation), not to speak of the required motor functions.

To choose the appropriate method to measure proprioceptive accuracy, the first step is to decide which aspect of proprioception one wants to assess: the sense of joint position, trajectory, speed, movement, force, muscle tension, weight, or size. For researchers, theoretical consideration may guide this decision, while for practitioners, ecological validity may be the most important factor. It is important to consider if the acuity of perception of afferent or both afferent and efferent information is the goal. In the former case, one should use a passive test (where participants do not have to conduct active movement or effort), in the latter case an active test is the appropriate. Different aspects can be measured with the method of adjustment, method of constant stimuli or with the method of limits (Gescheider, 1997; Han et al., 2016). Besides the measurement method, always the appropriate joint and body side should be measured with the relevant stimuli intensity (i.e. joint position, speed, trajectory, force, contraction level, weight or size.). Importantly, one should be aware that results obtained with a given technique are not generalizable for other techniques nor for other joints.

\section{Acknowledgements}

Á. H. was supported by the ÚNKP-20-3 New National Excellence Program of the Ministry for Innovation and Technology from the source of the National Research, Development and Innovation Fund. (ÚNKP-20-3-II-ELTE-163). N. J. was supported by the Special Research Fund (BOF) of Hasselt University (BOF19KP08). 


\section{Literature}

Aman, J. E., Elangovan, N., Yeh, I.-L., \& Konczak, J. (2015). The effectiveness of proprioceptive training for improving motor function: A systematic review. Frontiers in Human Neuroscience, 8. https://doi.org/10.3389/fnhum.2014.01075

Barrack, R. L., Skinner, H. B., Cook, S. D., \& Haddad, R. J. J. (1983). Effect of articular disease and total knee arthroplasty on knee joint-position sense. Journal of Neurophysiology, 50(3), 684-687. https://doi.org/10.1152/jn.1983.50.3.684

Cameron, M., Adams, R., \& Maher, C. (2003). Motor control and strength as predictors of hamstring injury in elite players of Australian football. Physical Therapy in Sport, 4(4), 159-166. https://doi.org/10.1016/S1466-853X(03)00053-1

Cho, Y. R., Hong, B. Y., Lim, S. H., Kim, H. W., Ko, Y. J., Im, S. A., \& Lee, J. I. (2011). Effects of joint effusion on proprioception in patients with knee osteoarthritis: A single-blind, randomized controlled clinical trial. Osteoarthritis and Cartilage, 19(1), 22-28.

https://doi.org/10.1016/j.joca.2010.10.013

Cullen, K. E. (2004). Sensory signals during active versus passive movement. Current Opinion in Neurobiology, 14(6), 698-706. https://doi.org/10.1016/j.conb.2004.10.002

de Jong, A., Kilbreath, S. L., Refshauge, K. M., \& Adams, R. (2005). Performance in different proprioceptive tests does not correlate in ankles with recurrent sprain. Archives of Physical Medicine and Rehabilitation, 86(11), 2101-2105.

https://doi.org/10.1016/j.apmr.2005.05.015

Docherty, C. L., Arnold, B. L., \& Hurwitz, S. (2006). Contralateral force sense deficits are related to the presence of functional ankle instability. Journal of Orthopaedic Research : Official Publication of the Orthopaedic Research Society, 24(7), 1412-1419. https://doi.org/10.1002/jor.20195

Docherty, C. L., Arnold, B. L., Zinder, S. M., Granata, K., \& Gansneder, B. M. (2004). Relationship between two proprioceptive measures and stiffness at the ankle. Journal of Electromyography \& Kinesiology, 14(3), 317. SPORTDiscus with Full Text. 
Edmonds, G., Kirkley, A., Birmingham, T. B., \& Fowler, P. J. (2003). The effect of early arthroscopic stabilization compared to nonsurgical treatment on proprioception after primary traumatic anterior dislocation of the shoulder. Knee Surgery, Sports Traumatology, Arthroscopy, 11(2), 116-121. https://doi.org/10.1007/s00167-003-0346-y

Elangovan, N., Herrmann, A., \& Konczak, J. (2014). Assessing Proprioceptive Function: Evaluating Joint Position Matching Methods Against Psychophysical Thresholds. Physical Therapy, 94(4), 553-561. https://doi.org/10.2522/ptj.20130103

Feng, J., Hung, T.-M., Huang, R., Hou, S., \& Ren, J. (2020). Role of Proprioception in Slow and Rapid Movements. Perceptual and Motor Skills, 127(2), 281-298.

https://doi.org/10.1177/0031512519895632

Gallagher, S. (2005). How the body shapes the mind. Clarendon Press.

Gescheider, G. A. (1997). Psychophysics: The fundamentals, 3rd ed (pp. x, 435). Lawrence Erlbaum Associates Publishers.

Goble, D. J. (2010). Proprioceptive acuity assessment via joint position matching: From basic science to general practice. Physical Therapy, 90(8), 1176-1184. https://doi.org/10.2522/ptj.20090399

Goble, D. J., \& Brown, S. H. (2007). Task-dependent asymmetries in the utilization of proprioceptive feedback for goal-directed movement. Experimental Brain Research, 180(4), 693-704. https://doi.org/10.1007/s00221-007-0890-7

Goble, D. J., \& Brown, S. H. (2008). Upper Limb Asymmetries in the Matching of Proprioceptive Versus Visual Targets. Journal of Neurophysiology, 99(6), 3063-3074. https://doi.org/10.1152/jn.90259.2008

Goble, D. J., Coxon, J. P., Van Impe, A., Geurts, M., Doumas, M., Wenderoth, N., \& Swinnen, S. P. (2011). Brain activity during ankle proprioceptive stimulation predicts balance performance in young and older adults. The Journal of Neuroscience: The Official Journal of the Society for Neuroscience, 31(45), 16344-16352. https://doi.org/10.1523/JNEUROSCI.4159-11.2011 
Goble, D. J., Noble, B. C., \& Brown, S. H. (2009). Proprioceptive target matching asymmetries in lefthanded individuals. Experimental Brain Research, 197(4), 403-408. https://doi.org/10.1007/s00221-009-1922-2

Grob, K. R., Kuster, M. S., Higgins, S. A., Lloyd, D. G., \& Yata, H. (2002). Lack of correlation between different measurements of proprioception in the knee. The Journal of Bone and Joint Surgery. British Volume, 84(4), 614-618. https://doi.org/10.1302/0301-620x.84b4.11241

Hams, A., Evans, K., Adams, R., Waddington, G., \& Witchalls, J. (2019). Throwing performance in water polo is related to in-water shoulder proprioception. Journal of Science and Medicine in Sport, 22, S39-S40. https://doi.org/10.1016/j.jsams.2019.08.213

Han, J., Anson, J., Waddington, G., \& Adams, R. (2013). Proprioceptive performance of bilateral upper and lower limb joints: Side-general and site-specific effects. Experimental Brain Research, 226(3), 313-323. https://doi.org/10.1007/s00221-013-3437-0

Han, J., Waddington, G., Adams, R., \& Anson, J. (2013). Bimanual proprioceptive performance differs for right- and left-handed individuals. Neuroscience Letters, 542, 37-41. https://doi.org/10.1016/j.neulet.2013.03.020

Han, J., Waddington, G., Adams, R., Anson, J., \& Liu, Y. (2016). Assessing proprioception: A critical review of methods. Journal of Sport and Health Science, 5(1), 80-90. https://doi.org/10.1016/j.jshs.2014.10.004

Han, J., Waddington, G., Anson, J., \& Adams, R. (2015). Level of competitive success achieved by elite athletes and multi-joint proprioceptive ability. Journal of Science and Medicine in Sport, 18(1), 77-81. https://doi.org/10.1016/j.jsams.2013.11.013

Hillier, S., Immink, M., \& Thewlis, D. (2015). Assessing Proprioception: A Systematic Review of Possibilities. Neurorehabilitation and Neural Repair, 29(10), 933-949. https://doi.org/10.1177/1545968315573055

Hoang, P. D., Baysan, M., Gunn, H., Cameron, M., Freeman, J., Nitz, J., Low Choy, N. L., \& Lord, S. R. (2016). Fall risk in people with MS: A Physiological Profile Assessment study. Multiple 
Sclerosis Journal - Experimental, Translational and Clinical, 2, 2055217316641130.

https://doi.org/10.1177/2055217316641130

Horváth, Á., Vig, L., Ferentzi, E., \& Köteles, F. (2021). Cardiac and Proprioceptive Accuracy Are Not Related to Body Awareness, Perceived Body Competence, and Affect. Frontiers in Psychology, 11. https://doi.org/10.3389/fpsyg.2020.575574

Isaac, S. M., Barker, K. L., Danial, I. N., Beard, D. J., Dodd, C. A., \& Murray, D. W. (2007). Does arthroplasty type influence knee joint proprioception? A longitudinal prospective study comparing total and unicompartmental arthroplasty. The Knee, 14(3), 212-217. https://doi.org/10.1016/j.knee.2007.01.001

Janwantanakul, P., Magarey, M. E., Jones, M. A., Grimmer, K. A., \& Miles, T. S. (2003). The effect of body orientation on shoulder proprioception. Physical Therapy in Sport, 4(2), 67-73. https://doi.org/10.1016/S1466-853X(03)00032-4

Khasnis, A., \& Gokula, R. M. (2003). Romberg's test. Journal of Postgraduate Medicine, 49(2), 169.

Li, L., Ji, Z.-Q., Li, Y.-X., \& Liu, W.-T. (2016). Correlation study of knee joint proprioception test results using common test methods. Journal of Physical Therapy Science, 28(2), 478-482. https://doi.org/10.1589/jpts.28.478

Liberati, A., Altman, D. G., Tetzlaff, J., Mulrow, C., Gotzsche, P. C., loannidis, J. P. A., Clarke, M., Devereaux, P. J., Kleijnen, J., \& Moher, D. (2009). The PRISMA statement for reporting systematic reviews and meta-analyses of studies that evaluate healthcare interventions: Explanation and elaboration. BMJ, 339(jul21 1), b2700-b2700. https://doi.org/10.1136/bmj.b2700 Lönn, J., Djupsjöbacka, M., \& Johansson, H. (2001). Replication and discrimination of limb movement velocity. Somatosensory \& Motor Research, 18(1), 76-82. https://doi.org/10.1080/08990220020021375 
Lord, S. R., Ward, J. A., Williams, P., \& Anstey, K. J. (1994). Physiological factors associated with falls in older community-dwelling women. Journal of the American Geriatrics Society, 42(10), 1110-1117. https://doi.org/10.1111/j.1532-5415.1994.tb06218.x

Lundy-Ekman, L. (2013). Neuroscience - E-Book: Fundamentals for Rehabilitation. Elsevier Health Sciences.

MacKinnon, C. D. (2018). Sensorimotor anatomy of gait, balance, and falls. Handbook of Clinical Neurology, 159, 3-26. https://doi.org/10.1016/B978-0-444-63916-5.00001-X

Miall, R. C., \& Wolpert, D. M. (1996). Forward Models for Physiological Motor Control. Neural Networks: The Official Journal of the International Neural Network Society, 9(8), 1265-1279.

Moher, D., Liberati, A., Tetzlaff, J., Altman, D. G., \& Group, T. P. (2009). Preferred Reporting Items for Systematic Reviews and Meta-Analyses: The PRISMA Statement. PLOS Medicine, 6(7), e1000097. https://doi.org/10.1371/journal.pmed.1000097

Nagai, T., Allison, K. F., Schmitz, J. L., \& Sell, T. C. (2016). Conscious Proprioception Assessments in Sports Medicine: How Individuals Perform Each Submodality? Sports Med, Sports Med: SM Online Scientific Resources, 13.

Newport, R., Hindle, J. V., \& Jackson, S. R. (2001). Links between vision and somatosensation: Vision can improve the felt position of the unseen hand. Current Biology, 11(12), 975-980. https://doi.org/10.1016/S0960-9822(01)00266-4

Niespodziński, B., Kochanowicz, A., Mieszkowski, J., Piskorska, E., \& Żychowska, M. (2018). Relationship between Joint Position Sense, Force Sense, and Muscle Strength and the Impact of Gymnastic Training on Proprioception. BioMed Research International, 2018, 1-10. https://doi.org/10.1155/2018/5353242

Okuda, T., Ochi, M., Tanaka, N., Nakanishi, K., Adachi, N., \& Kobayashi, R. (2006). Knee joint position sense in compressive myelopathy. Spine, 31(4), 459-462. https://doi.org/10.1097/01.brs.0000199956.11646.5b 
Proske, U., \& Gandevia, S. C. (2012). The proprioceptive senses: Their roles in signaling body shape, body position and movement, and muscle force. Physiological Reviews, 92(4), 1651-1697. https://doi.org/10.1152/physrev.00048.2011

Ribeiro, F., \& Oliveira, J. (2007). Aging effects on joint proprioception: The role of physical activity in proprioception preservation. European Review of Aging and Physical Activity, 4(2), 71-76. https://doi.org/10.1007/s11556-007-0026-x

Riemann, B. L., \& Lephart, S. M. (2002). The Sensorimotor System, Part II: The Role of Proprioception in Motor Control and Functional Joint Stability. Journal of Athletic Training (National Athletic Trainers' Association), 37(1), 80. SPORTDiscus with Full Text.

Sarlegna, F. R., \& Sainburg, R. L. (2009). The Roles of Vision and Proprioception in the Planning of Reaching Movements. Advances in Experimental Medicine and Biology, 629, 317-335. https://doi.org/10.1007/978-0-387-77064-2_16

Sevrez, V., \& Bourdin, C. (2015). On the Role of Proprioception in Making Free Throws in Basketball. Research Quarterly for Exercise and Sport, 86(3), 274-280.

https://doi.org/10.1080/02701367.2015.1012578

Shumway-Cook, A., \& Horak, F. (1986). Assessing the Influence of Sensory Interaction on Balance: Suggestion from the Field. Physical Therapy, 66, 1548-1550. https://doi.org/10.1093/ptj/66.10.1548

Shumway-Cook, A., \& Woollacott, M. H. (2007). Motor Control: Translating Research Into Clinical Practice. Lippincott Williams \& Wilkins.

Sole, G., Osborne, H., \& Wassinger, C. (2015). The effect of experimentally-induced subacromial pain on proprioception. Manual Therapy, 20(1), 166-170. https://doi.org/10.1016/j.math.2014.08.009

Stillman, B. C. (2002). Making Sense of Proprioception: The meaning of proprioception, kinaesthesia and related terms. Physiotherapy, 88(11), 667-676. https://doi.org/10.1016/S0031$9406(05) 60109-5$ 
Stillman, B. C., \& McMeeken, J. M. (2001). The role of weightbearing in the clinical assessment of knee joint position sense. Australian Journal of Physiotherapy, 47(4), 247-253. https://doi.org/10.1016/S0004-9514(14)60272-5

Subasi, S. S., Gelecek, N., \& Aksakoglu, G. (2008). Effects of different warm-up periods on knee proprioception and balance in healthy young individuals. Journal of Sport Rehabilitation, 17(2), 186-205. https://doi.org/10.1123/jsr.17.2.186

Suprak, D. N., Osternig, L. R., van Donkelaar, P., \& Karduna, A. R. (2006). Shoulder joint position sense improves with elevation angle in a novel, unconstrained task. Journal of Orthopaedic Research : Official Publication of the Orthopaedic Research Society, 24(3), 559-568. https://doi.org/10.1002/jor.20095

Waddington, G., \& Adams, R. (1999). Ability to discriminate movements at the ankle and knee is joint specific. Perceptzral and Motor Skills, 89, 1037-1041.

Wingert, J. R., Welder, C., \& Foo, P. (2014). Age-Related Hip Proprioception Declines: Effects on Postural Sway and Dynamic Balance. Archives of Physical Medicine and Rehabilitation, 95(2), 253-261. https://doi.org/10.1016/j.apmr.2013.08.012

Witchalls, J., Blanch, P., Waddington, G., \& Adams, R. (2012). Intrinsic functional deficits associated with increased risk of ankle injuries: A systematic review with meta-analysis. British Journal of Sports Medicine, 46(7), 515-523. https://doi.org/10.1136/bjsports-2011-090137

Yang, N., Waddington, G., Adams, R., \& Han, J. (2020). Joint position reproduction and joint position discrimination at the ankle are not related. Somatosensory \& Motor Research, 37(2), 97-105. PsycINFO. https://doi.org/10.1080/08990220.2020.1746638

Yokoyama, S., Matsusaka, N., Gamada, K., Ozaki, M., \& Shindo, H. (2008). Position-specific deficit of joint position sense in ankles with chronic functional instability. Journal of Sports Science \& Medicine, 7(4), 480-485. 